\title{
LESIONS OF THE CORPUS STRIATUM IN CHILD. HOOD, WITH REPORT OF CLINICAL CASES ILLUSTRATING VARIOUS SYNDROMES *
}

\author{
BRONSON CROTHERS, M.D. \\ BOSTON
}

Every physician who deals with any considerable number of children with paralysis of cerebral origin is impressed by the fact that the motor disturbances vary enormously in type. Most common, perhaps, is the conventional spastic type, either hemiplegic or paraplegic, with scissors gait, contractures and increased reflexes. Others show bizarre abnormalities of motion, speech defect and changes of muscle tone, without great variations in reflexes. Mental defectiveness of any degree may accompany the motor manifestations.

Pathologically, a wide variety of lesions have been described, and the searcher in the literature is left with a confused idea that so many causes may produce cerebral palsy, that it is useless to try to localize lesions accurately.

As a result children with cerebral palsies have, to a large extent, been grouped as essentially hopeless, except as tenotomies or nerve section might relieve disabling spasticity or contracture. Classification has been distinctly unsatisfactory, and a considerable array of names, mostly descriptive of symptoms, has added to the confusion.

This paper is written to put before pediatricians certain facts, recently established by workers in several countries, and to show that lesions of the corpus striatum can logically account for the symptoms of a group of children with motor disabilities, who show disturbance of associated movements, variations in muscle tone and defects of speech. I believe that accurate prognosis and logical therapeutic efforts will be assisted by the separation of these cases from other cerebral palsies.

Six cases are presented to show some of the different syndromes resulting from lesions of the corpus striatum in childhood. Of course, it is obvious enough that, without necropsies, such cases are not conclusive, but a study of the literature, and frequent consultation with others, convinces me that there are sound reasons for classifying the cases definitely.

\footnotetext{
* Received for publication May 9, 1921.

* From the Children's Hospital, Boston, and The Department of Neurology, Harvard Medical School.
} 


\section{HISTORICAL}

During the past ten years several researches of fundamental importance, reinforced by numerous reports of carefully studied clinical cases, have done much to clarify our conception of disturbances of motility.

In 1895, Anton ${ }^{1}$ described a case of bilateral athetosis with lesions largely confined to the putamen of the lenticular nucleus. Little importance was attached to Anton's paper until 1911, when Cecile Vogt, ${ }^{2}$ working with Oppenheim ${ }^{3}$ and others, ${ }^{4}$ confirmed Anton's work and established the fact that lenticular lesions were frequently found in necropsies on cases showing bilateral athetosis. In 1911, Wilson " published a classical paper on lenticular degeneration with cirrhosis of the liver. Five years later Hunt ${ }^{6}$ described cases of juvenile paralysis agitans with lesions of the lenticular nuclei. From 1908 to the present time various papers have been published tending to show that dystonia deformans, a disease characterized by variations of muscle tone leading to extraordinary deformities, and athetosis, is also due to lenticular disease. Various contributions have been published on other diseases, such as Huntington's chorea and paralysis agitans, which add weight to the conviction that the corpus striatum is a fundamental factor in the control of motility.

\section{ANATOMIC CONSIDERATIONS}

The gross anatomy of the corpus striatum is well known. Under this term I include the lenticular and the caudate nuclei. The caudate nucleus lies in the floor of the lateral ventricle. In part, it is continuous with the lenticular nucleus and in part it is separated from it by the fibers of the internal capsule. The lenticular nucleus, almost entirely surrounded by medullated fiber tracts, is divided into an inner portion, the globus pallidus, and an outer portion, the putamen. It is the putamen which joins, in front, the caudate nucleus. Figures 1, 2, and 3 illustrate the relations of the corpus striatum.

1. Anton, G.: Ueber die Beiteiligung der grossen basalen Gehirn-ganglien bei Bewegungsstörungen und insbesondere bei Chorea. Jahrb. f. Psychiat. 14:141, 1895. 1911.

2. Vogt, C.: Syndrome du corps strié. J. f. Psychiat. u. Neurol. 18:478,

3. Vogt, C. and Oppenheim, H.: Wesen und Localization der kongenitalen und infantilen Pseudobulbarparalyse. J. f. Psychiat. u. Neurol. 18:293, 1911.

4. Freund, C. S. and Vogt, C.: Etat Marbré, etc. J. f. Psychiat. u. Neurol. 18:489, 1911 .

5. Wilson, S. A. K.: Progressive Lenticular Degeneration with Cirrhosis of Liver, etc., Brain 34:295, 1911. 1917. 
Wilson ' demonstrated, in the ape, the fiber connections of the corpus striatum. He showed that the caudate and the putamen are intimately bound to each other and to the globus pallidus. No fibers cross between the corpora striata of opposite sides. No fibers pass to the cortex or to the pyramidal tracts. Fibers from the corpus striatum pass to the thalamus and to certain subthalamic structures, notably to the red nucleus. Tracts, or fibers, from the thalamus and subthalamic nuclei enter the corpus striatum. Connection with the cord is assumed through synapses in the red nuclei and the rubrospinal tracts.

Microscopically two main types of cells are found: (1) Large cells, of the type elsewhere associated with motor activity. These are chiefly

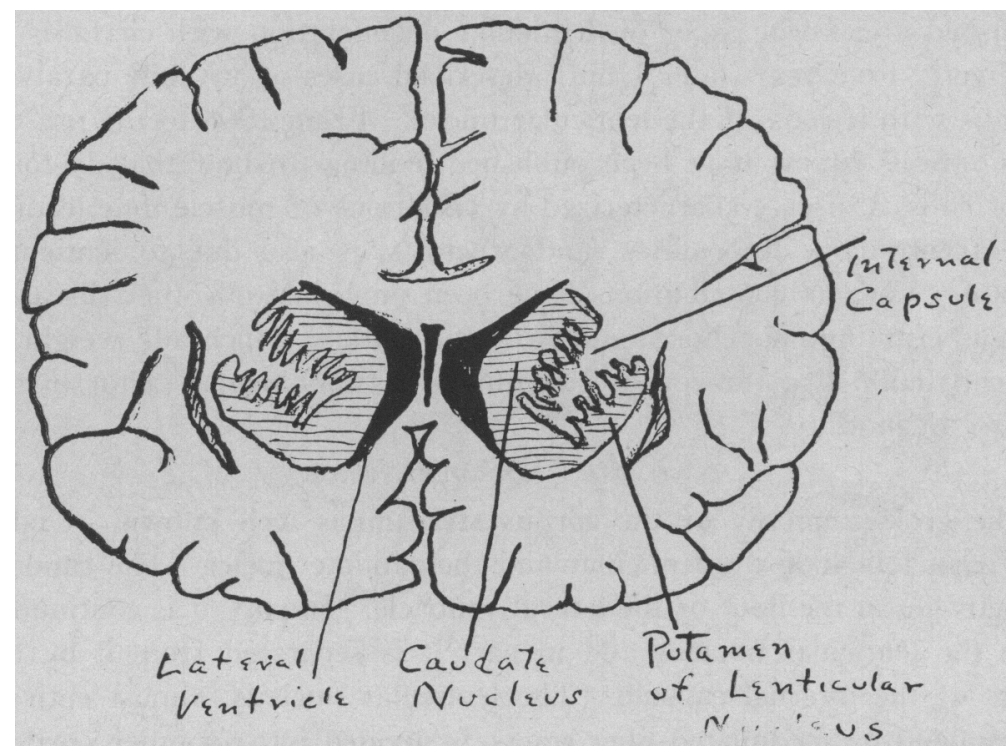

Fig. 1.-Frontal section of brain through anterior part of corpus striatum, showing putamen and caudate, partly separated by internal capsule.

found in the globus pallidus, and as they are phylogenetically and ontogenetically older than the other cells of the corpus striatum, they are called, collectively, the paleostriatum. Hunt proposes that these large cells be known as the pallidal system, including those scattered through the putamen and the caudate. (2) Small cells, younger in development, form the bulk of the cellular elements in the putamen and caudate. This group is known as the neostriatum.

\section{PJIYSIOLOGIC CONSIDERATIONS}

In cats, section of the brain just above the red nuclei produces the decerebrate rigidity of Sherrington. The animal remains rigid, with

7. Wilson, S. A. K.: Experimental Research into the Anatomy and Physiology of the Corpus Striatum, Brain 36:427, 1914. 
extension of the legs, stiffness of the back and arching of the neck and tail. If by a more anterior section, the basal ganglia are left, but the cortex removed, progressive movements are possible. The suggestion is obvious that the progressive associated movements are controlled in some way by the basal ganglia. As the thalamus is apparently purely sensory in function, it is reasonable to suppose that the corpus striatum is the responsible factor.

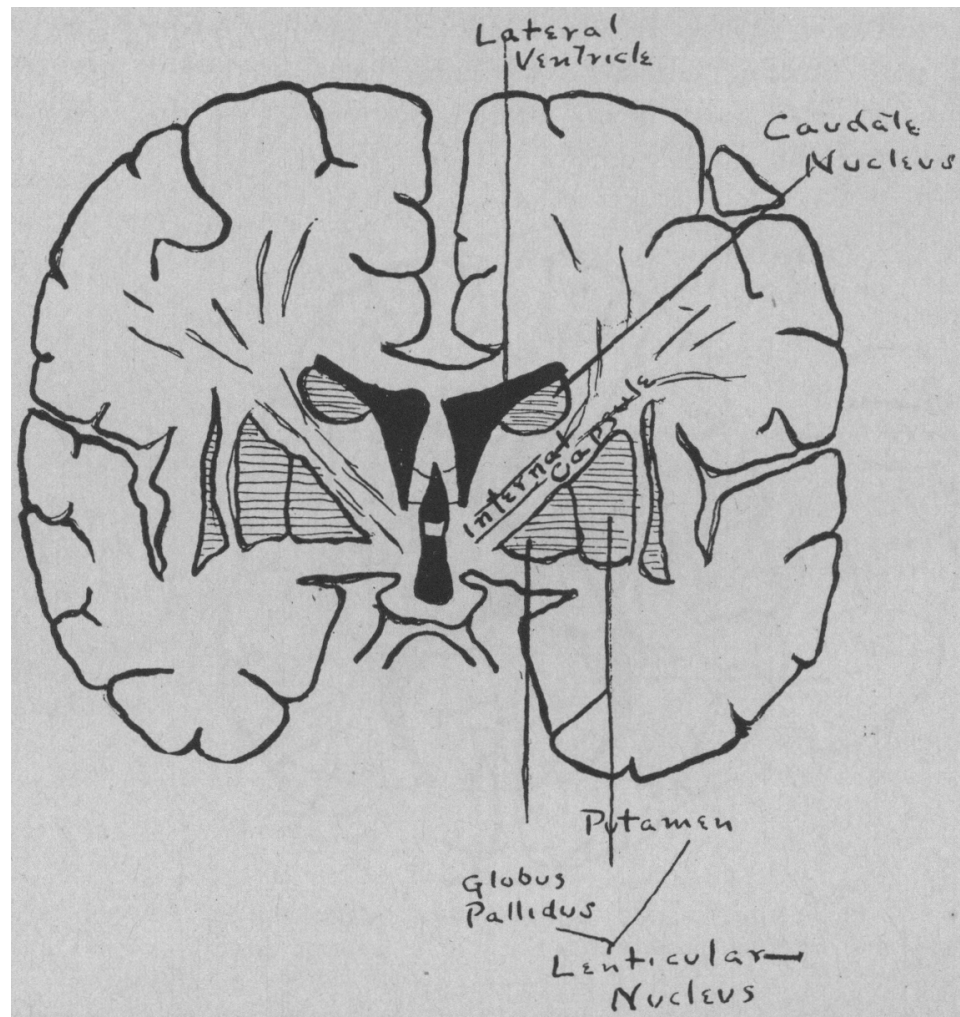

Fig. 2.-Frontal section of brain through the foramen of Munro, showing capsule separating the caudate from the lenticular nucleus which now includes globus pallidus.

Wilson, ${ }^{7}$ working with Horsley, attempted to reproduce clinical syndromes by destruction of the corpus striatum in apes. Though his work was fruitful from the point of view of fiber tract study, he failed to produce definite motor disturbances. It is particularly noteworthy, that he was unable to produce motor activity in any way comparable with the motor manifestations obtained by cortical stimulation.

\section{PATHOLOGIC AND CLINICAL CONSIDERATICNS}

Anatomically, we have seen that the corpus striatum of each hemisphere consists of a small celled neostriatum closely connected with a 
group of cells larger in size and motor in type, called the paleostriatum. The paleostriatum is independent of cortex and pyramidal tracts, but closely linked by afferent fibers with the thalamus and associated nuclei and by efferent fibers with subthalamic groups of cells, of which the red nucleus seems the most important.

Physiologically, meager evidence of control of associated movements is alone available.

Fortunately, sharply localized lesions of the corpus striatum, associated with striking clinical syndromes, clear up many points, and allow us to get a fairly good working knowledge of the function of the lenticular and caudate nuclei.

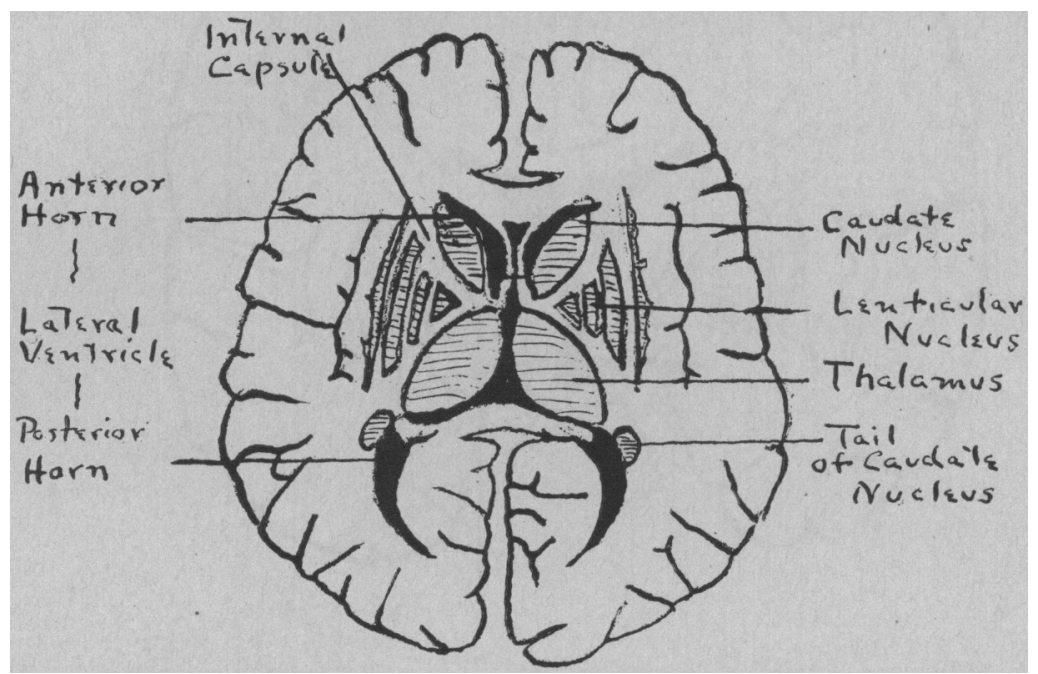

Fig. 3.-Horizontal section of brain showing relations of corpus striatum, ventricles and internal capsule.

For purposes of understanding the various types of disorder to be described, it is necessary to straighten out the nomenclature. Many authors refer to the lenticular nucleus as the corpus striatum, neglecting entirely the caudate. For practical purposes, the so-called lenticular lesions will be assumed to cover lesions of the entire corpus striatum, except as they are limited to the paleostriatum or the neostriatum. This, perhaps, unjustified assumption is made in order to avoid constant explanation. Every histologic and anatomic consideration makes it probable that the caudate and the putamen are essentially a unit, quite artificially set apart by the internal capsule.

The following syndromes are fairly well defined and more or less thoroughly established pathologically and help to a clear conception of the rôle of the corpus striatum: 
1. Double athetosis, as described by Anton and Vogt. Here we have choreiform or athetoid movements, especially apparent on intention, with frequent difficulty in speech and swallowing. Associated movements are disturbed, but rigidity is relatively slight. Ocular movements are normal and reflexes are not disturbed. Clinically, this picture suggests a disorder of control rather than a paralysis. Pathologically, the small neostriatal cells are chiefly affected. Vogt has described the lesion as état marbré. The streaks of white seen in the sections are apparently due to myelinated fibers, replacing the degenerated ce.lular elements.

The course of this disease is peculiar. Starting at birth, or in early childhood, there is little progression and the condition is consistent with a long and mentally normal life. Occasional occurrence of two cases in one family is noted.

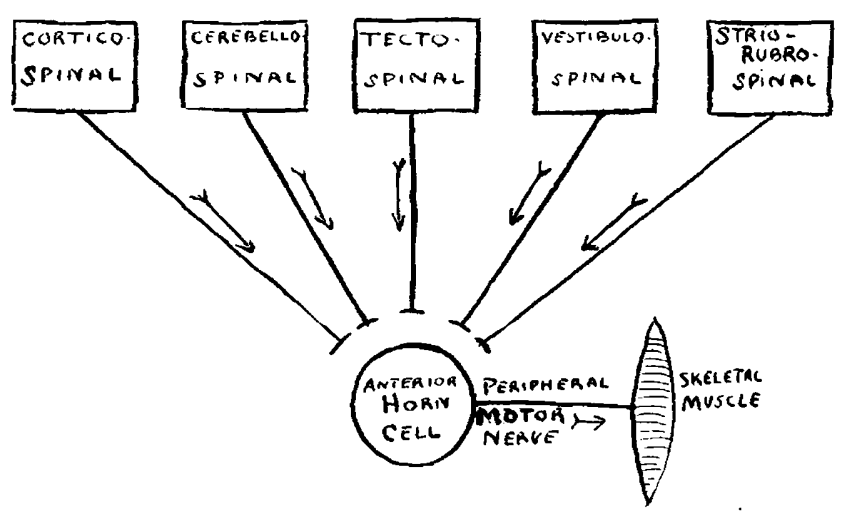

Fig. 4.-Diagram showing main tracts infuencing motility of skeletal muscle. For clearness cerebellar impulses are grouped, though, actually, they are exerted through various paths.

2. Juvenile paralysis agitans, as described by Hunt, consists of extreme rigidity with tremor, without choreiform or athetoid movements. It is progressive and leads to helplessness and spechlessness, without, necessarily, mental impairment. The reflexes, except as masked by rigidity, are normal.

Pathologically, the large motor cells of the paleostriatum are involved. Hunt regards the disease as essentially a paralysis of associated movement.

3. Rigidity, tremor and, occasionally, choreiform or tonic spasms occur in the progressive lenticular degeneration with cirrhosis of the liver, described by Wilson. In these cases both neostriatum and paleostriatum are involved. Hunt regards Wilson's syndrome as essentially rigidity plus chorea, but it is obvious that certain of Wilson's cases showed only tremor and rigidity. Steady progressive disability 
leads to death in a few years. In Wilson's cases a remarkable family tendency was observed. No clear hereditary factors have been worked out.

4. Dystonia lenticularis; a disease characterized by a wide variety of athetoid movements, made even more bizarre by differences in tone between various muscle groups. This tone variation leads to more or less permanent deformities of which the characteristic dromedary back, shown in photographs of Case 1, is the most typical. Regarded by its first describers as a neurosis it was not until Thomalla's ${ }^{8}$ paper in 1918 that careful pathologic studies showed changes in the putamen of the lenticular nucleus and liver changes, thus establishing, for the present, its status as a disease of the lenticular region. Taylor ${ }^{9}$ summarizes recent literature and reiterates Thomalla's argument that intermediate forms, linking together the various syndromes, occur.

These four syndromes are associated with clean cut lesions of very definite type. However, anyone reading case reports is struck by the extremely atypical character of certain of the symptoms in cases where autopsy confirmed the diagnosis.

For example, Thomalla's case of dystonia showed, for a short time, the prolonged muscular contractions usually associated with Thomsen's disease (myotonia congenita), while other cases show Babinski's phenomenon, unequal reflexes, etc.

In addition to these four groups in which lesions are confined to the corpus striatum, there are many cases in which the disturbed involuntary movements, so characteristic of lenticular lesions, occur in children showing, in addition, indisputable evidence of lesions of the corticospinal neurones, that is, spasticity, exaggerated reflexes, Babinski's phenomenon or clonus. This is not unexpected if we realize the intimate relations of the internal capsule and the corpus striatum. Furthermore, it is a commonplace that the "arteries of cerebral hemorrhage" are those of lenticulostriate groups, which supply the capsules and parts of the basal ganglia. This group of cases presents, naturally, a wide variety of clinical pictures, depending on the extent of the lesions and the relative damage to capsule and nuclei. Except for Thomas's ${ }^{10}$ cases, I have found no reference to family susceptibility. Apparently this combined involvement of the capsule and the corpus striatum can be the result of hemorrhage or of degenerative processes.

8. Thomalla, C.: Ein Fall von Torsionsspasmus mit Sektionsbefund und seine Beziehungen zur Athétose double, Wilsonische Krankeit und Pseudosclerose, Ztschr. f. d. ges. Netrol. u. Psychiat. 41:311 (June) 1918.

9. Taylor, E. W.: Dystonia Lenticularis, Arch. Neurol. \& Psychiat. 4:417 (Oct.) 1920.

10. Thomas, J. J.: Chronic Progressive Lenticular Degeneration with Mental Deterioration, J. Nerv. \& Ment. Dis. 47:320 (Nov.) $19 ! 7$. 
From a consideration of these various facts it is possible to arrive at fairly definite conclusions.

It seems clear that the paleostriatum is the motor center for certain associated movements, which are controlled and steadied by the neostriatum. This mechanism functions without direct connection with the corticospinal neurones. This idea of an autononous motor system is carried further by Hunt ${ }^{11}$ who has developed the hypothesis that the peripheral nervous system has one set of fibers for pyramidal impulses and another for impulses arising in the corpus striatum. He further regards it as probable that these two groups act on different elements in the muscle tissue. His work is backed up by a considerable body of clinical and physiological evidence and must be followed with the greatest interest.

The present view of motor control of other observers is based chiefly on Sherrington's ${ }^{\mathbf{1 2}}$ conception that the anterior horn cell with its axis cylinder forms the final common path over which all impulses to the muscle must pass. Figure 4 shows the chief motor tracts. The lesions of the various tracts cause specific disorders, as follows:

1. Corticospinal: Spastic paralysis with increased reflexes and Babinski's phenomenon.

2. Cerebellospinal: (Under this name are grouped all fibers acted on by cerebellar cells, though they constitute no definite single tract), ataxia, asynergia, atonia and the like.

3. Tectospinal: Disordered reflexes depending on sight and hearing.

4. Vestibulospinal: Vertigo and disturbances of balance.

5. Striorubrospinal: The results of lesions of this tract are those discussed in this paper and consist of disorders of associated movements and variations in muscle tone.

It is obvious from Figures 1,2 and 3 that lesions of the corpus striatum may involve the corticospinal tracts leading to such combinations of athetosis and spasticity, as are frequently seen in hemiplegias due to lesions of the lenticulostriate arteries.

Hunt's conception, of course, demands two final common paths, one of which is acted on by the first four tracts, while the second receives its chief impulses from the corpus striatum alone.

Probably, we cannot obtain typical corticospinal spasticity as a result of cerebral lesions without relatively intact striorubrospinal tract, and vice versa. This is strikingly suggested by the fact that an ordinary

11. Hunt, J. R.: Transmission of Motor Impulses in Peripheral Nerves, Brain $41: 302,1918$. 1905.

12. Sherrington, C. S.: Integrative Action of Nervous System, New Haven, 
hemiplegia, occurring in a patient with paralysis agitans, produces paralysis without tremor or spasticity on the affected side. As the pyramidal lesion clears the tremor and rigidity return.

A consideration of the various fundamental papers, with due weight given to the numerous case reports now available, leads to the question of grouping. No entirely satisfactory nomenclature is available. This phase of the question will be considered again, in connection with the case reports.

However, from the point of view of treatment, two main groups are suggested. In the first would fall Wilson's disease, dystonia lenticularis and juvenile paralysis agitans. These syndromes are, apparently, the result of symmetrical degenerative lesions; they are progressive, and offer little hope for arrest or for effective treatment. On the other hand, the cases of double athetosis, and certain cases showing a mixture of spasticity and disturbed associated movements are, as far as I have learned, usually not progressive and are reasonably hopeful. In many of these cases, it seems probable that hemorrhagic lesions are responsible. Naturally, pathologic classification is uncertain, as most of the patients are still alive.

Racial factors seem to influence the form of the disease, as the majority of cases classified as dystonia occur in Jewish children.

One very important point should be considered, and that is the proper use of the term cerebral spastic paralysis. Strictly speaking, this should include both groups, the pyramidal, and the lenticular lesions with rigidity. But it seems more reasonable to classify cases as corticospinal or pyramidal, if the lesion involves those neurones, or as lenticular or extrapyramidal, if the lenticular apparatus is responsible.

The judgment of mental status is singularly difficult. The patients are almost always restricted to a very narrow life and speech difficulties are usually marked. No doubt, many children are judged too severely and regarded improperly as idiots or imbeciles. The combination of set expression and speech defect with extreme awkwardness creates an impression of defective mentality that is hard to overcome. Anyone who has had any considerable experience in checking clinical impressions by psychological tests realizes the enormous possibility of error.

\section{CASE REPORTS}

CASE 1.-One form of the progressive type of disease: The boy suffers from tremor, hypertonicity and rigidity of muscles, without any of the ordinary signs produced by corticospinal lesions.

Clinical diagnosis.-Progressive bilateral degeneration of lenticular nuclei, of type described by Wilson, except for certain features suggestive of dystonia lenticularis. 
C. F., 9 years and 9 months old, was admitted to the orthopedic wards on Aug. 3, 1918.

Family History.-Parents, healthy Irish people. One sister and one brother well. (Two years later still well, except one child "not developing mentally." I have been unable to obtain an exact report on the abnormal child.)

Previous History.-Entirely normal childhood until present illness.

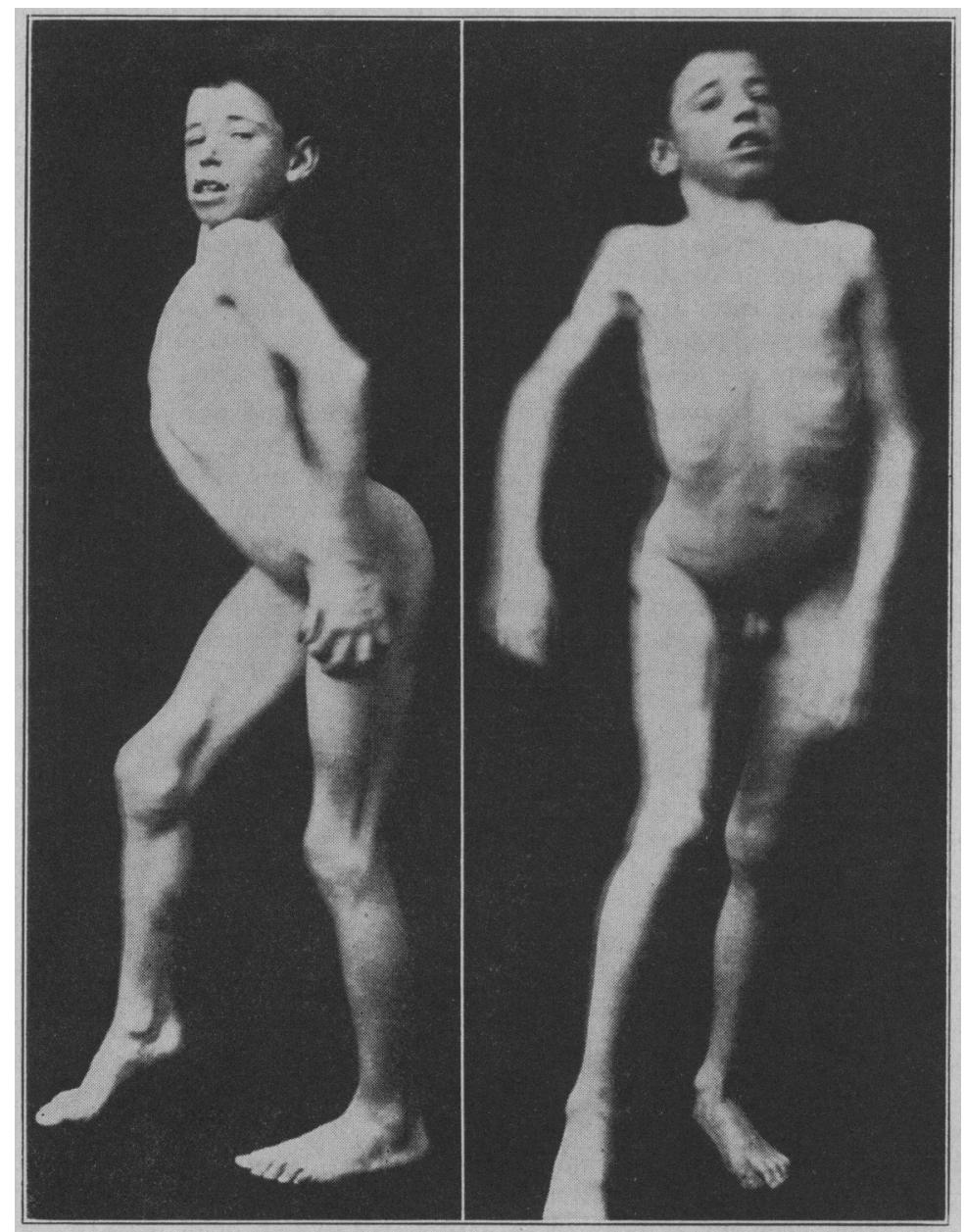

Fig. 5. Case 1.-Showing "dromedary back." Exposure of 1/50 second. The lack of distinction in hands is due to tremor.

Present Ilness.-Five weeks before entrance. father noticed that boy carried one shoulder forward, and a few days later he began to stand crookedly.

Physical Examination.-Not remarkable, except for the following: Speech slow, without definite scanning quality. Walking difficult and movements seemed ataxic, or at least he had difficulty in balancing. All his movements were slow and awkward. Deformities, attributed to muscle rigidity, were right torticollis, right dorsal and left lumbar scoliosis. He usually kept the right 
leg bent at the hip and knee. On lying down, all these abnormalities of posture cleared up. Reflexes, extra-ocular movements and fundi were entirely normal. He was discharged at the end of two weeks with the symptomatic diagnosis of myotonia.

Clinical Course.-Jan. 19, 1921 he was readmitted for further study by request of Dr. Robert W. Lovett, to whom I am indebted for the privilege of seeing and reporting this case.

During the past two and one-half years, the boy attended school regularly and had not been regarded as an invalid at home. His school work was satisfactory and his parents saw no reason for worry.

I saw him Jan. 23, 1921. He was sitting comfortably at a table and at first glance seemed quite normal. On attracting his attention, it was clear that he understood perfectly well what went on, but his facial expression did not change at all and a rather extreme smile persisted. His lower lip trembled, and occassionally a few drops of saliva dripped over it. His speech was clear and expressed his ideas unusually well for a boy of his age. No scanning quality was observed, although at times his words came jerkily and slowly. On attempts to read aloud he had difficulty with long or unfamiliar words and their pronunciation was accompanied by coarse tremor of arms and legs.

Second Physical Examination.-This showed a boy of normal stature and development. Facial expression as described. No evidence of paralysis. Eyes entirely normal including fundi, extraocular movements and fields of vision. Tongue protruded straight with slight tremor. Lower lip almost constantly tremulous with occasional escape of saliva. Palate moved normally. The rest of the body showed general rigidity. The outlines of all muscles were clearly visible and the constant slow tremor of certain groups was very striking. The individual muscles stood out sharply and alternate contraction and relaxation was clearly seen. The rigidity was most marked in the larger muscles and the small muscles of the hand and foot seemed definitely hypotonic. His posture clearly suggested variations in tone in the great trunk and thigh muscles. On tapping the muscles, sudden appearance of localized swelling was observed. Following the rapid disappearance of this swelling a tâche cerebralé appeared. Voluntary control and accurate movements of all muscle groups were observed. The awkwardness was obviously due to rigidity, tremor or involuntary movements, rather than to any lack of pyramidal control. Sensation, both deep and superficial, was entirely undisturbed. Closing of the eyes did not increase awkwardness or tremor. The reflexes, deep and superficial were entirely normal.

The mental status of the patient, whether judged by school progress, general impression or formal test was normal. By the Stanford revision of the Binet-Simon test he graded $1011 / 12$ against a chronologic age of $114 / 12$. His handwriting was clear, though he stated it was hard to use a light pen or pencil. With a strong pencil and by the use of considerable pressure, he managed to overcome tremor. But when he was uncertain as to exact lines, as in the Binet problem of drawing a path in a circular field, marked tremor occurred. In fact, this single test showed his condition almost perfectly. The problem, found in the Stanford test for 8 years, is to find a base ball in a circular field. The subject is asked to draw his path inside a two and one-half inch circle and to continue until the ball is found. The boy solved the problem perfectly, by starting in a spiral. He was able to keep his rings about an eight of an inch apart, but the early part of the course showed continuous tremor, while as he became certain of the correct solution he drew a heavier and steadier line. On the tests requiring accurate memory and straight lines very little tremor was observed. Duritg the test he occasionally burst into tears, without any other evidence of real emotion or excitement. 
COMMENT

Further observation of the patient was most instructive. The picture as described is one dominated by rigidity, tremor and contractures. On the next day the character of the involuntary movements had decidedly altered. He showed a surprising variety of athetoid movements and relatively little rigidity. Variations in the signs occurred almost from hour to houx By those who saw him and were familiar with recent literature, a variety of diagnosis were made. Dystonia, double athetosis and Wilson's syndrome were all given, as the dominant signs came and went. More than any other case, in my experience, this boy showed unmistakable disturbance of the corpus striatum with a shifting clinical picture. Muscle tone also varied. Usually it was decidedly less in the fingers and toes than in the larger muscle groups.

No doubt exists that this case is one of double lenticular disease. The stiff smile, the tremulous lips with occasional escape of saliva, the rigidity and tremor with athetosis, make an unmistakable picture. On the whole, it seems to fit into the same category as Wilson's cases. The posture, on the other hand, suggests dystonia. Against dystonia, in its typical form, is the absence, as a rule, of bizarre involuntary movements, and to a certain extent his Irish parentage. However, the exact classification is unnecessary as the prognosis is not altered. Treatment is discouraging, as no way of stopping the steady progress of the tremor, rigidity and athetosis is known. All that can be done is to attempt to train the boy to do things that can be carried on as long as possible. The presumption is strong that total disability will occur within a very few years.

CASF 2.-This is an example of a congenital, or birth, lesion. His histery shows that at first his motor disturbance was flaccid, later of the type usually associated with corticospinal lesions, finally becoming athetoid without spasticity.

Clinical Diagnosis.-Double athetosis, probably due to double denticular lesions, caused by birth injury or by failure of development.

M. L. the sixth child of Jewish parents, entered the medical outpatient department of the Children's Hospital, May 15, 1915, aged 1 year.

Family History.-Mother and father living and well. Three other children living and well. Two died in infancy.

Previous History.-Easy labor. Small child, said to weigh only 4 pounds at birth. There was a question as to whether he was one month premature. No asphyxia or convulsions were observed.

Present Illness.-At the end of his first year he was not walking or sitting up without support and was brought to the hospital. A careful examination showed no evidence of spasticity or definite paralysis, and a diagnosis of rickets was made. He was frequently reexamined and the diagnosis was not changed until February, 1916, when he was sent to a state school for feeble minded.

He returned to the hospital in July, 1918, on account of failure to walk. Examination on the orthopedic service showed the following condition. A boy, aged 4 , obviously mentally defective, with moderate rickets. Choreiform 
movements of the face, spasm of adductors of thighs and gastrocnemii. Knee jerks hyperactive, with bilateral clonus at knee and ankle. Babinski on both sides suggestive. Moderate contractures of both Achilles tendons.

A diagnosis of spastic paralysis involving both legs was made and tenotomies of Achilles tendons were done. No note of any speech defect was made.

Following recovery from his operation, he returned to the outpatient department where, by training, he was enabled to walk with support.

In July, 1920, he was sent to receive further muscle training without splints. Brief notes describe his gait as extremely unsteady, showing ataxia and incoordination.

In November, 1920, I saw him for the first time. The impression of feeblemindedness was partly confirmed by the Stanford revision of the Binet test, which gave him a mental age of $4 \frac{1}{2}$ years, against a chronologic age of $6 \frac{1}{2}$. It is to be said that the impression of greater retardation was obvious and $I$

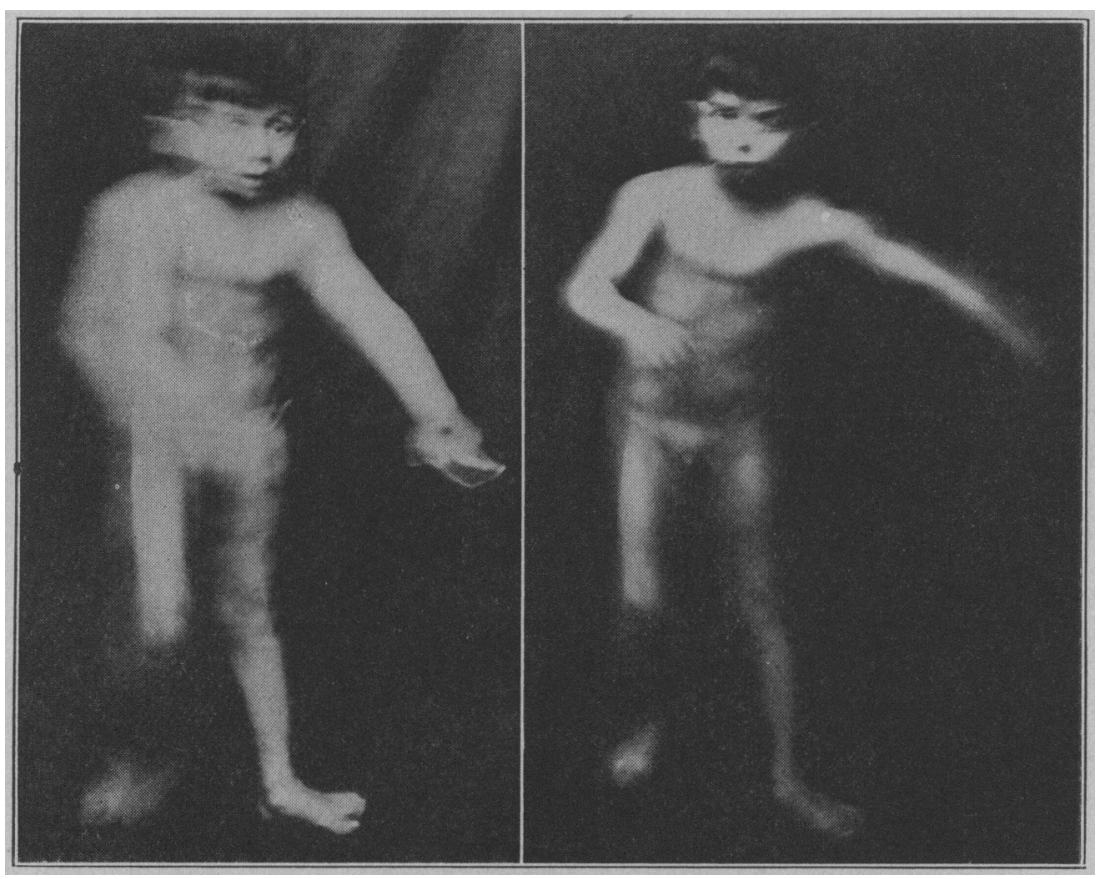

Fig. 6. Case 2.-The photographs suggest the quick, almost squirming torsion and the athetosis shown by this patient. These pictures were the clearest of a series of many taken with $1 / 50$ second exposure.

was surprised at his ability to handle the mental test. Furthermore. I am not yet convinced that the Binet test does not underestimate the intelligence of children who are deprived of ordinary social contacts and schooling.

Physical Examination.-His general attitude is shown in Figure 6. During the entire examination, he showed a constantly changing picture of uncontrolled movements, sparing only the eyes. No cranial nerve paralyses were made out. All external eye muscles were functioning and no nystagmtis was apparent. Visual fields, by rough test were normal, the tongue protruded straight, there was no palatal paralysis. $\mathrm{His}$ speech was extremely jerky and often almost impossible to interpret, but no aphasia existed. On attempting unfamiliar words he went through a series of contortions involving his whole borly, before being able to articulate. 
The examination of the skeletal muscles showed no paralysis. The muscles were stiff, without obvious differences in tone between various groups. Any abnormalities of posture were due to temporary muscular contractions rather than to permanent deformities.

His reflexes were entirely within normal limits. No Babinski or other extensor phenomena could be elicited. No clonus was observed. I particularly searched for evidence of contracture or spasm of adductors, hamstrings, or gastrocnemii and found none. Associated movements showed bizarre abnormalities. When walking, his arms moved without any relation to his legs. He was able to walk with considerable freedom, but the whole frame was involved in continuous athetosis and extreme effort was necessary to make progress. No sensory disturbances existed, as far as tests on a retarded child could be considered conclusive.

\section{COMMENT}

In babyhood this boy was regarded as a rachitic idiot. Following a two year stay in an institution for feeble minded, he showed conclusive signs of pyramidal tract involvement; spasticity, clonus and contractures, with some involuntary movements of the face, and was operated on at four years. At $61 / 2$ years he showns no signs of pyramidal tract involvement, but a clean cut picture of the type associated with lesions of the corpus striatum.

It seems reasonable to suppose that the pathologic processes in the corpus striatum involved, at one stage, the pyramidal tracts, by pressure. This would correpond with one case reported by Vogt, who found evidence of pyramidal tract pressure, manifested by apparent enlarge ment of the internal capsule, due to spreading of the fibers. Furthermore it is interesting to note that, in Cases 4 and 5 and in those reported by Thomas, ${ }^{12}$ the pyramidal tracts were clearly involved in lesions clinically, primarily localized in the corpus striatum.

Another interesting feature was the error in judgment made in estimating his mentality. The impression of idiocy was far from confirmed by the result of formal testing, which showed a much higher level of intelligence than the appearance of the child suggested.

CASE 3.-This case is reported in order to show a type of cerebral palsy, without spasticity, which, I believe, is due to pure lesions of the corpus striatum. It also shows slow improvement under treatment.

P. S., aged $4 \frac{1}{2}$ years, was seen in December, 1920 , in consultation. She is the only child of healthy parents. A few hours before her birth her mother had a rather troublesome uterine hemorrhage. Otherwise nothing to excite notice occurred until the latter part of her first year. At that time it was observed that she failed to sit up.

She never developed control over her muscles, or learned to sit alone or to walk. No systematic attempt at muscle training had been made. She learned to talk at about the usual time, but speech had always been difficult to understand. As far as the parents or the family physician know, no diagnosis beyond "cerebral disease" had ever been made by any of the various consultants who had seen the child.

Physical Examination.-This showed an extremely bright attractive child smiling cheerily. However, the impression of vivacity rather diminished 
during the course of examination as the smile persisted throughout. Athetosis was marked, except for the face. Particularly when trying to speak, movements were very lively. The eyes showed no pupillary abnormalities. The extraocular movements were normal; there was no nystagmus and rough tests showed no limitation of visual fields. The other cranial nerves showed no evidence of involvement. The tongue protruded straight, without tremor. The mouth was held open, without evidence of nasal obstruction, or escape of saliva. A very definite fixed smile was present at all times. Dysarthria was marked, though practically all words were intelligible. No dysphagia.

The disturbances of the motor control of the trunk and limbs were very marked. Athetosis and disturbances of associated movements were particularly striking. It was impossible to close one hand, for example, and hold the other extended. Attempts at walking were grotesquely awkward, until a definite slow rhythm was adopted and then she managed fairly well, with support. Her muscles were all moderately rigid, though no spasm or contracture existed. Furthermore all muscles were well developed. No definite variations in tone were made out. Knee jerks, ankle jerks, the deep reflexes of the arm and the superficial reflexes of the abdomen were all normal. No Babinski or Oppenheim could be elicited. Sensation was normal to touch and pain and, as far as could be judged, muscle sense was not impaired. No increase of unsteadiness was observed when the child closed her eyes. Voluntary movements of all muscles were possible, and except as rigidity and involuntary motions interfered, were accurate.

No formal mental test seemed worth while, as the complete isolation of the child's life, her inability to handle concrete material and her speech defect made judgment by test practically worthless. However, she very certainly was not seriously retarded. Naturally her parents and relatives had indulged every known wish, in spite of this she was tractable in most things and very responsive and affectionate.

Under carefully supervised muscle training she nas gained appreciably in control in the course of four months.

\section{COMMENT}

The diagnosis here is hardly in doubt. The congenital nature of the disease, its apparently nonprogressive character, the facial expression, the normal extra-ocular movements, the normal reflexes and the generalized disturbance of associated movement all point conclusively to double lenticular lesions. The presumption is that the lesion is that described by Cecile Vogt as état marbré of the lenticular nucleus involving, chiefly, the cells of the neostriatum.

The treatment followed is based, largely, on theoretic grounds. In a child of normal mentality a condition, which is presumably not progressive, disturbs the control of involuntary movements. The corticospinal neurons are apparently intact, as is muscle sense. I do not see why suitable muscle training should not develop a reasonably effective motor system. Of course, rigidity and involuntary movements will probably persist. In any case, the thorough trial of this method offers a promising field.

In Case 2 such a method, with a patient of inferior intelligence is resulting in a very decided improvement, even under unfavorable home conditions. 
Further treatment can be carried out, which falls under the general term of mental hygiene. It is, of course, essential that the child be trained to obedience. The possibility of handling the various problems that inevitably will face her, with reasonable serenity, depends almost entirely on the intelligent supervision that she is able to have at present.

CASE: 4.-A girl, aged $4^{1 / 2}$ years, showing bilateral athetosis and spasticity without demonstrable mental defect.

Clinical Diagnosis.-Bilateral lesions of corpus striatum, with involvement of internal capsules, probably due to birth hemorrhages.

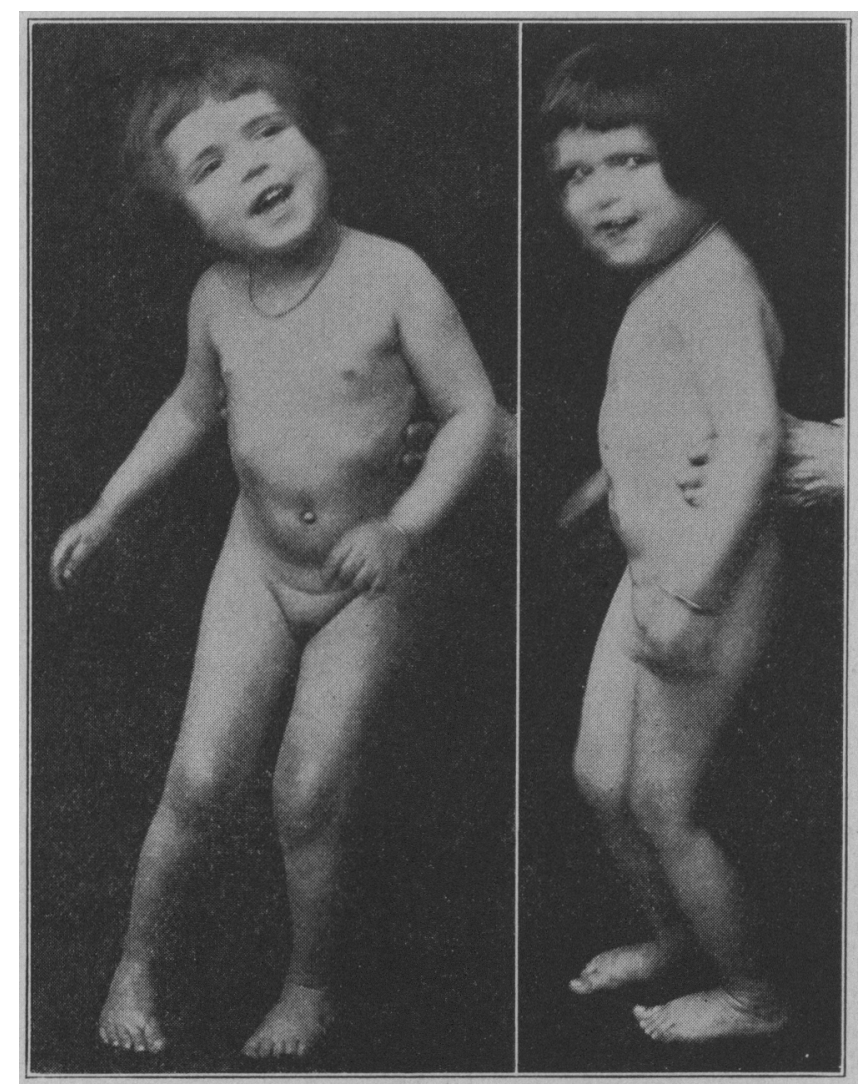

Fig. 7. Case 4.--Illustrating the bright facial expression and the absence of conventional "spastic" posture or contractures.

- M. B. was scen March 31, 1921, in the Nerve Outpatient Department. She is $4 \frac{1}{2}$ years old and is the only child of healthy parents. She was delivered, after twenty-four hours of labor, by forceps. Asphyxia was marked, and she required artificial respiration for a considerable time. No convulsions or stupor followed.

During the first year she appeared normal and began to speak at one year. At 18 monhs she trierl to walk, withont success. Since babyhood she has 
apparently developed normally as far as mentality is concerned. Her speech is difficult to follow, but she uses a considerable vocabulary accurately, on the other hand, she has developed little motor control and is entirely unable to use her hands accurately or to walk.

Physical Examination.-Shows a well developed and bright child. Except for her motor system she shows no abnormality. No paralysis of cranial nerves exists. No nystagmus, no abnormality of pupils or eyegrounds. The difficulty in speech seems to be due to incoordination of the muscles, rather than to any other factor. The mouth remains open and occasionally there is escape of saliva. The arms and legs are distinctly stiff. This stiffness, which is definitely plastic in type, is more marked on the right side. Reflexes are lively, particularly on the right, where they are defnitely above normal. Both plantar reflexes are extensor in type with fanning of the toes. A well sustained ankle clonus is present on the right and a few jerks can be elicited on the left.

Motor disturbances are very striking. Attempts at movement give rise to a variety of definitely athetoid movements. The usual attitude of "spastic paralysis" is conspicuously absent. She attempts to walk with her feet wide apart and every step is accompanied by all sorts of aimless movements of her arms. Indiviudal muscles can be used efficiently and easily, and it seems clear that difficulties arise only when smooth coordination of various groups is necessary.

No ataxia, disturbance of muscle sense or superficial sensory disorder can be made out.

\section{COMMENT}

This child illustrates, I believe, a rather common condition. The most reasonable explanation is that she had, at birth, hemorrhages in the region of the lenticular and caudate nuclei, involving the internal capsules. This would fit in with the very clear history of asphyxia. Her present condition is largely due, according to this conception, to destruction of the nuclei, with relatively little damage to the neighboring capsules. I believe that this case fits in between the pure lesion of the corpus striatum, of which Case 3 is an example, and the conventional spastic paralysis with adductor spasm and hamstring and Achilles contractures and so on.

The prognosis, of course, is doubtful, but I feel confident that the condition is not progressive, and that on the whole improvement is to be expected.

Treatment is as suggested for Case 3 .

CASE 5.-This case is reported in order to show an atypical case with degenerative lesions and mental retardation. In this child the internal capsules as well as the nuclei were apparently involved.

G. C., 8 years old, was first admitted to medical wards of the Children's Hospital Aug. 28, 1919.

Family History.-Negative; father, mother, one brother and two sisters living and well.

Previous History.-Full term, normal delivery. Chickenpox, bronchitis and r.easles. Otherwise entirely uneventful story till present illness.

Present Illness.-June 15, 1919, kept in bed two weeks for "St. Vitus dance." Mother noticed senseless laughter and some deterioration of mentality. Then up and about, without full recovery of motor control, until August 24, when she was again put to bed. Admitted to hospital the next day. 
During her stay in the hospital she had coarse tremor apparently of intention type, absent abdominal reflexes, ankle clonus at times on left, suggestive Babinski on left, no definite nystagmus. October 21, she was seen by Dr. E. W. Taylor who regarded her as having, probably, multiple sclerosis. She was discharged relieved Nov. 12, 1919.

From then until Jan. 2, 1920, she was followed by visitors who reported great speech difficulty and persistence of choreiform movements.

Second Examination.--On readmission she showed thickness of speech, occasional regurgitation of food through her nose and coarse tremor. Abdominal reflexes were not obtained, no clonus or Babinski were observed. Yo nystagmus. Discharged relieved March 28, 1920.

During the summer of 1920 , she apparently recovered entirely, except that she twitched more or less when excited and was decidedly irritable.

From November, 1920, she became increasingly shaky and was admitted to the wards Dec. 4, 1920, when she showed much the same picture as on previous occasions. No nystagmus, no serious speech disturbance, sluggish abdominal reflexes, double Babinski, and clonus on left. Tremor was confined to the left hand.

- Eye examination by Dr. H. W. Goodall showed congestion of both discs with decidedly defective vision.

I saw her repeatedly from January 6 to her discharge. When first seen, she smiled almost continuously with a rather vacant expression. Her movements were tremulous and at times definitely ataxic in character without accentuation on closing eyes. The eyes showed irregular up and down oscillations, but I could not determine that there was any nystagmus. No palsy of external eye muscles noted at first. Pupils equal and reacted normally. Tongue protruded straight with slight trembling. No palatal paralysis. No facial paralysis or asymmetry.

The arms were not stiff, reflexes normal. The left arm and hand were markedly tremulous with some movements suggesting athetosis. No weakness of any muscle group and firm contraction was easily maintained. Attempts to make definite coordinated movements resulted in ataxic tremulous movements. This disturbance was not increased by closing eyes and was apparently not due to impairment of muscle sense. The same phenomena in less degree were present on the right.

The legs showed bilateral ataxic movements, increased deep reflexes and, like the arms, apparently normal superficial and deep sensation. Babinski's phenomenon and clonus were present on left at first, later on both sides. Abdominal reflexes were obtained.

A Binet test showed a mental age of $6 \% / 12$ compared with her present age of 9. This agrees with previous estimates in the hospital and with a history of rather unsatisfactory school work in the second grade.

Comment.-This combination of spasticity, involuntary movements of mixed tremulous and choreiform type with mental retardation suggested the atypical lenticular degeneration described by Thomas. ${ }^{11}$ Dr. Thomas was good enough to see this patient. His examination disclosed, in addition to the previously described signs, a weakness of the right internal rectus with resultant diplopia. He agreed that the lesions were to be placed in both lenticular nuclei, with involvement of the pyramidal tracts.

This case does not fit into any definite group but the evidence is strong that both lenticular nuclei are involved. The remission suggests the possibility of the lesions being of the type of multip'e sclerosis. 
Against the ordinary type of multiple sclerosis is the repeated presence of abdominal reflexes, the absence of typical scanning speech and of typical nystagmus. Furthermore, no signs pointing to lesions elsewhere were obtained.

Chorea, in my opinion is unlikely for the following reasons. First, the prolonged course, second, the signs of definite pyramidal tract involvement and third, the ability to maintain a steady muscular contraction. Furthermore mental retardation is unusual in chorea, while it is common in lenticular degeneration.

I wish to thank Dr. John Lovett Morse for permission to study and report this puzzling case.

CASE 6.-This Jewish child, aged 7, with vague motor disturbance is presented, because he shows signs suggesting a mild involvement of the corpus striatum.

A tentative clinical diagnosis of lenticular degeneration was made.

J. D., 6 years and 10 months old, was admitted to Dr. J. L. Morse's service at the Children's Hospital Feb. 2, 1921. I am indebted to Dr. Morse for permission to see this case and report it.

Family History.-Negative. Both parents and two other children are well.

Previous History.-He was born at full term. Instruments were used and he had a bilateral cervical swelling, regarded by his physician as haemotomata. No asphyxia or convulsions occurred.

Present Illness.--The symptoms reasonably associated with his present condition were, first, a difficulty in getting his words out, without obvious lack of clear articulation. This speech defect existed from very early childhood and was increased following a tonsil operation in August 1920 . Second, a motor disturbance, which was first noticed one year before entrance. At that time he ran sideways and shook his head, without reason. Vaguely described squirming movements followed and have persisted. No special difficulty had been observed in handling objects. His parents regarded him as normal mentally, but interested neighbors, and finally the school doctor, told the parents he was backward and nervous and suggested sending him to the hospital for diagnosis.

Physical Examination.-A well developed and nourished child lay quietly in bed. The expression was quite abnormal. The eyes were alert and gave the impression of mental activity. The lower part of the face was almost entirely immobile. The mouth was not kept open. The impassive face, added to his speech defect, created an appearance of feeble mindedness.

No abnormality of eyesight, eye movements, or eye grounds was observed. No signs pointed to involvement of any cranial nerves.

The speech defect struck me as divisable into two parts, first a distinctly scanning rhythm with occasional jerky articulation, second clumsy phonation, which I felt could be explained by a considerable tear of the soft palate, apparently resulting from the tonsil operation.

The muscle of the trunk and limbs shared in curiously vague, rather slow involuntary movements. His posture was not normal as his back was perfectly straight, without any lumbar curve. No definite changes of tone were made out. On walking he showed no tremor of marked unsteadiness, but there was no smooth coordination of arms and legs, in fact sometimes one arm would hang motionless, while the other moved about without the slightest relation to the walking rhythm.

Careful sensory examination showed no change in deep or superficial sensation. 
Reflexes were normal, except that the left ankle jerk was decidedly lively and, at times two or three clonic jerks could be elicited. No Babinski was found. No paralysis existed.

Mental tests showed that the first impression of feeble mindedness was not justified. He had a mental age of $6 \% / 12$ compared with a chronological age of $61 \%$. The rest of the physical was negative except for a heart murmur regarded by $\mathrm{Dr}$. Morse as congenital, probably due to an abnormal interventricular septum. The liver extended from the fifth rib to the costal margin.

Comment.-I realize that this case is extremely vague and I quite agree with Dr. Morse in regarding the picture as too indefinite for positive diagnosis. The suggestive things, to my mind, are the following. A boy of 6 , with a definite speech abnormality develops involuntary movements which persist for a year. Further, his face is so lacking in expression that many people, including physicians, have called him feeble minded. His posture is abnormal. The atypical ankle clonus on one side suggests pyramidal tract involvement.

These various facts strongly suggest the probability of a lenticular lesion, either early or slight, and can be explained in no other way that seems satisfactory. Obviously he has "chorea" of an atypical sort. Also he may be simply "nervous," but nervousness lasting a year with entire lack of facial expression is in my experience, unusual.

This case again shows the danger and injustice of judging the mentality of these children without careful investigation.

\section{CONCLUSIONS}

A number of syndromes characterized by disturbances of associated movements, variations in muscle tone, and speech defects are definitely associated with sharply localized lesions of the corpus striatum. They are easily distinguished, in typical cases, from spastic pyramidal tract syndromes and from the ordinary chorea. In atypical cases confusion necessarily arises and careful sorting out of signs is essential. I believe that a critical reexamination of children showing involuntary movements over a period of months or years, will reveal unsuspected cases. Moreover, the cases of this short series demonstrate the dangers of relying on casual impressions in judging mental status, when speech defects and motor disorders complicate the picture.

Finally, it seems reasonable to consider, whether the recent advances in knowledge of disorders of the motor apparatus do not demand a more exact nomenclature for paralyses of cerebral origin.

From every point of view, the study of cases of the type here described is well worth while. The present classification is purely tentative and, as Taylor points out, is almost certainly too rigid. Pathological studies have been very few and aetiological data are extremely scanty. 
My recent experience with the syndromes shows fairly conclusively that such disorders cannot be considered rarities, and also demonstrates that general attention has not been called to this group.

Naturally, no claim is made that all cases like those reported are due to corpus striatum lesions alone. Abundant evidence shows that various other lesions may obscure and complicate the picture, and it is entirely likely that further study may modify the rather dogmatic and perhaps inaccurate views that are here set forth. ${ }^{13}$

I wish to express my gratitude to Miss Mary Trainor whose long experience as chief of the group of workers in the Nerve Outpatient Department has enabled her to advise and carry out therapeutic exercises in some of these cases.

13. For a full bibliography reference to Wilson's, Hunt's and Taylor's papers should be made. The following references also bear on this subject:

Cadwallader, W. B.: Pseudosclerosis, etc., Am. J. M. Sc. 150:556 (Oct.) 1915.

De Castro, A.: Des mouvements associés dans l'athetose, Rev. neurol. 24:368 (Oct. 15) 1912.

Frauenthal H. W. and Rosenheck, C.: Dystonia Deformans (Case report) J. Nerv. \& Ment. Dis. 52:134 (Aug.) 1920.

Gordon, A.: Extrapyramidal Hemiplegia, J. Nerv. \& Ment. Dis. 42:157 (March) 1915.

Hunt, J. R.: Torsion Spasm (Dystonia Deformans) J. A. M. A. 67:1430 (Nov. 11) 1916.

Marie, P. and Lhermitte, J.: Les lesions de la choree chronique progressive. Ann. de med. 1:18, 1914.

Rhein, J. H. W.: Extrapyramidal Motor Disturbances, J. Nerv. \& Ment. Dis. 42:802 (Dec.) 1915.

Spiller, W. G.: Family form of Pseudosclerosis, etc., J. Nerv. \& Ment. Dis. 43:23 (Jan.) 1916.

Stern, G.: Zum Krankheitsgilde der "Athétose double" Monatschr, f. Kinderh. 19:404 (Feb.) 1921.

Strumpell, A.: Wilsonische Krankheit, etc., Deutsch. Ztschr. f. Nervernh.

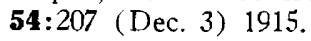

